\title{
INVEST
}

INVEST Working Papers 16/2020

\section{Parental divorce homogamy and its effect on separation from cohabitation and marriage}

Sanna Kailaheimo-Lönnqvist

Anette Fasang

Marika Jalovaara

Emanuela Struffolino 
The Inequalities, Interventions, and New Welfare State (INVEST) aims at increasing wellbeing of Finnish society during childhood, youth and early adulthood and preventing psychosocial risks compromising such development through innovative interventions. Based on cutting-edge research on the conditions and mechanisms involved at different periods of development, INVEST will evaluate and develop various universal and targeted interventions to improve the efficiency of the current welfare state institutions at critical points of the early life course. INVEST aims at providing a new model for the welfare states that is more equal, better targeted to problem groups, more anticipatory as well as economically and socially sustainable. INVEST is a Flagship project of the Academy of Finland. 


\title{
Parental divorce homogamy and its effect on separation from cohabitation and marriage
}

\author{
Sanna Kailaheimo-Lönnqvist ${ }^{1}$, Anette Fasang ${ }^{2,3}$, Marika Jalovaara ${ }^{1}$, Emanuela Struffolino ${ }^{3,4}$. \\ ${ }^{1}$ University of Turku, ${ }^{2}$ Humboldt University of Berlin, ${ }^{3}$ WZB, ${ }^{4}$ Freie Universität Berlin
}

\begin{abstract}
Numerous studies have shown that parental divorce increases children's divorce risk. We extend this literature by assessing how parental divorce on both sides of a (potential) couple affects their partnering dynamics. Specifically, we explore 1) whether there is parental divorce homogamy and whether the parental divorce of both partners adds to the dissolution of both 2) cohabiting and 3) married unions. Our analyses use event history models on high-quality Finnish Census Panel data covering 28,021 cohabiting and marital partnerships between ages 18 and 45. We found substantial parental divorce homogamy in that children who experienced parental divorce are $13 \%$ more likely to cohabit with and $17 \%$ more likely to marry a fellow child of divorce. Moreover, contrary to evidence from the United States and Norway, our findings for Finland support an additive, not a multiplicative, effect. Here, both partners' parental divorce increases their offspring's dissolution risk by $20 \%$ for cohabitation and $70 \%$ for marriage compared to couples where neither of their parents are divorced. We conclude that parental divorce on both sides of a couple affects family formation processes at multiple stages. In Finland, these effects are notably less than previously found in the United States. This is likely because cohabitation and separation are wide-spread and socially accepted in Finland and an expansive welfare state buffers the socio-economic consequences of divorce.
\end{abstract}

Keywords: divorce, cohabitation, union dissolution, intergenerational relations 


\section{Introduction}

In recent decades, divorce and separation have become more common across many affluent democracies. This contributes to an increase in family complexity (Thomson 2014). Numerous studies show that parental divorce increases their offspring's divorce risk (Amato 1996; de Graaf and Kalmijn 2006; Diekmann and Schmidheiny 2013; Dronkers and Härkönen 2008; Kulu 2014; Lyngstad and Jalovaara 2010; Wolfinger 2007). Possible mechanisms that drive the intergenerational transmission of union dissolution include socio-economic status transmission, social learning of attitudes and interpersonal behaviours from parents, and a lower threshold for one's own divorce or separation as it was observed in one's parents (Amato 1996; Amato and DeBoer 2001; Review: Lyngstad and Jalovaara 2010). For cohabiting couples, the same mechanisms are likely in place, although their baseline risk of union dissolution (irrespective of parental divorce) is higher compared to married couples (Jalovaara 2013; Jalovaara and Kulu 2018; Steele et al. 2005).

Union dissolution has numerous consequences for adults and children. For adults, consequences include new phases of living alone, single and non-residential parenthood, and the possible formation of new partnerships and stepfamilies. For women, union dissolution from both marriage and cohabitation, to a similar degree, are negatively associated with socioeconomic standing (Avellar and Smock 2005). Divorced households are often singleincome households that are at a higher risk of poverty (Hübgen 2018; Smock et al. 1999), particularly for those with lower education or weak labor market attachment before or after union dissolution. This is typically the case for divorced mothers with resident children. Contrarily, some studies show increased income among divorced men (Breusch and Gray 2004).

Parental divorce also affects children's up-bringing and family formation. Studies suggest that children of divorce are likely to grow up with fewer socio-economic resources and role models for inter-personal behavioral skills (such as compromising and conflict resolution) to maintain long-lasting relationships. Furthermore, they hold pro-divorce attitudes (e.g., Amato 1996). They are also more likely to marry early or late and go through a divorce (Amato 1996; Kulu 2014; Lehrer 2008; Moore and Waite 1981; Storksen et al. 2007).

Most studies focus on simple parent-child dyads to examine the intergenerational transmission of divorce. Yet separations are negotiated within couples. To our knowledge, to date, only three studies have examined how parental divorce on both sides of a couple impacts 
offspring divorce risk (These are: Amato 1996; Storksen et al. 2007; and Wolfinger 2003). For the United States, Amato (1996) reports that both spouses' parental divorce triples their divorce risk. He largely attributes this to the compound effect of poor interpersonal skills of both spouses that accumulate, causing conflict. Using different data for more recent groups in the US, Wolfinger (2003) corroborates the three times elevated likelihood of divorce for couples where both parents are divorced compared to couples were neither parents are divorced. In addition, children of divorced parents are $31 \%$ more likely to marry a fellow child of divorce. Further, Wolfinger (2003) concludes that parental divorce homogamy is a major demographic predictor of divorce by multiplicatively compounding risk factors for offspring divorce.

The findings might be specific to the United States, where marriage is particularly culturally idealized in spite of high divorce and remarriage rates and the socioeconomic consequences of divorce are severe, particularly for women, due to limited welfare provisions (Cherlin 2010). In Norway, Storksen et al. (2007) report slightly lower effects for both parental divorce homogamy and the elevated divorce risk when both spouses' parents are divorced, although their offspring divorce risk still almost triples. The Nordic countries are forerunners in partnership changes associated with a second demographic transition. Here, family formation sets in later compared to the United States and cohabitation and separation are more widespread and culturally accepted. Further, a comparatively generous welfare state with individualized entitlements buffers the socio-economic consequences of divorce. Arguably the intergenerational transmission of divorce and the joint effect of both parents' divorce on offspring divorce are weaker in such contexts. None of the above studies have examined the effect of both partners' parental divorce on separation risks from cohabitation. Yet, how parental divorce affects the stability of cohabiting unions is increasingly relevant as the prevalence of long-lasting cohabitations grows in countries in advanced stages of the second demographic transition. Neglecting cohabitation separation could overlook a substantial part of the elevated separation risk due to parental divorce if children of divorce tend to cohabit rather than marry.

In this paper, we ask how parental divorce on both sides of a couple affects the couple's family dynamics more broadly, focusing on Finland as a representative of the Nordic welfare state model. First, we ask whether there is parental divorce homogamy, that is, are children of divorce more likely to partner with fellow children of divorce. Second, we investigate to what extent both partners' parental divorce increases the dissolution of cohabiting, and third, of married unions. Examining the effects of parental divorce from both 
sides of a couple at multiple stages of the family formation process enables us to assess its impact more comprehensively beyond divorce from marriage. We use exceptionally rich representative register data for Finland that allows us to follow entire co-residential partnership histories between the ages of 18 and 45 and link each cohabiting and married partnership to both partners' parental divorce. Parental divorce homogamy is analyzed with logit models. The effect of both partners' parental divorce on dissolution risks in cohabitation and marriage is estimated with piecewise constant exponential event history models with frailty adjustments.

The contribution of this study is threefold. First, we comprehensibly account for the entire prior co-residential partnership history from ages 18 to 45 as a pathway through which elevated separation risks are passed from one generation to the next, including parental divorce homogamy. If children of divorcees are more likely to partner with each other, the joint impact of both partners' parental divorce becomes relevant for a larger share of the population. Second, we assess whether the effect strength of parental divorce homogamy and elevated separation risks when both partners' parents are divorced are, indeed, weaker in the Nordic welfare state of Finland compared to the United States. Third, to our knowledge, we present the first study that compares these associations for both cohabiting and married couples. Cohabitation is gaining importance as it proliferates as a substitute, not only a prelude, for marriage. Cohabitation is associated both with lower socio-economic standing and a higher baseline union dissolution risk compared to marriage in Finland (Jalovaara 2013). In addition, children of divorce may be more likely never to marry (Glenn and Kramer 1987), but will cohabit instead. If dual parental divorce is concentrated among cohabiting couples and elevates their separation risk, this could additionally reinforce the cohabiting couple's socio-economic disadvantages compared to married couples.

\section{Background}

\section{Previous research}

Numerous studies show that parental divorce increases children's divorce risk and that intergenerational divorce transmission is stronger in some contexts than others (de Graaf and Kalmijn 2006; Diekmann and Schmidheiny 2013; Dronkers and Härkönen 2008; Jalovaara and Kulu 2018; Lyngstad and Jalovaara 2010). For example, transmission is weaker in countries where divorce among the parent generation was more common (Dronkers and Härkönen 2008) and less socially stigmatized (Kalmijn and Uunk 2007). Moreover, a meta-analysis on 120 
European divorce studies shows that lower divorce barriers in a society are associated with weaker intergenerational divorce transmission (Wagner and Weiß 2006).

As divorce proliferates, its intergenerational transmission might become weaker, but, among couples where both partners' parents are divorced, it is likely to become more prevalent. Because union dissolution occurs between two people, both partners' experiences of parental divorce are relevant when estimating the risk of union dissolution. Compared to the sizeable literature on intergenerational divorce transmission in simple parent-child dyads, the couple level of both partner's experiencing of parental divorce has received much less attention. According to our knowledge, only three previous studies explore this topic (Amato 1996; Storksen et al. 2007; Wolfinger 2003).

All three previous studies support elevated divorce risks of up to three times when both spouses' parents are divorced. For the United States, Amato (1996) and Wolfinger (2003) find that these couples' divorce risks are three times higher compared to couples in which neither partner experienced parental divorce. This suggests a multiplicative, rather than an additive, effect of parental divorce for both sides of the couple. The authors interpret the triple increase in divorce risks could be caused by both partners lacking interpersonal relationship skills that would ordinarily lead to marital stability. Storksen and co-authors (2007) used register data for one Norwegian county that the assume to be largely representative of Norway to show a somewhat less elevated divorce risk for couples in which both partners' parents divorced. The increase is almost tripled but the interaction effect between spouses' parents' divorce was not significant. Storksen et al. (2007) conclude that, surprisingly, parental divorce from both sides of the couple increases divorce risks in a similar magnitude as in the United States, despite lower overall divorce transmission and a welfare state that more effectively mitigates the socioeconomic consequences of divorce.

These studies do not consider dissolution among cohabiting couples. As noted by Storksen and colleagues (2007), if offspring of divorce are more likely to cohabit and separate from cohabitation, parental divorce might contribute to many more separations of coresidential unions than are captured in estimates of divorce transmission only. Moreover, cohabitation is becoming increasingly wide-spread in many countries. Despite the growing popularity of cohabitation, marriage and cohabitation differ in many respects. Most marriages start with cohabitation in Finland (Jalovaara 2012) and couples that continue to cohabit often remain in lower socio-economic statuses compared to couples who eventually marry (Jalovaara 2013; Jalovaara and Kulu 2018). Marriage is still an important norm signaling ultimate 
commitment and marriages have lower general dissolution risks than cohabiting relationships (Jalovaara 2013; Jalovaara and Kulu 2018; Steele et al. 2005).

\section{Mechanisms of divorce transmission}

Mechanisms that transmit union dissolution (and union formation) from parents to children comprise socio-economic status transmission, socialization (including pro-divorce attitudes and interpersonal relationship skills), and biological and genetic transmission (Fasang and Raab 2014). These mechanisms partly play out and are reinforced by partnership histories preceding union dissolution (Lyngstad and Jalovaara 2010), including the age of leaving home, marrying, partner selection, and cohabitation. Concerning status transmission, it is wellestablished that lower socio-economic status and lower education are associated with an elevated separation risk (Amato 2010; Jalovaara 2001; Kulu 2014). Because socio-economic status and low education are transmitted from one generation to the next, divorce transmission might arise as a by-product of status transmission.

Socialization and social learning refer to the norms and values about desirable and appropriate family lives that children learn in their parental home in early childhood (Fasang and Raab 2014). Norms include expectations about the appropriate timing and order of specific events over one's life and social stigma associated with non-normative family transitions such as union dissolution. Moreover, the strength of perceived divorce stigma varies between families. Children who have experienced parental divorce generally stigmatize separation less than children whose parents have not divorced, and thus separating is seen as more acceptable (Dronkers and Härkönen 2008). Socialization also includes a behavioral component. Relationship skills are observed and learned in the parental home (Wolfinger 2003). If union dissolution is triggered by weak interpersonal skills between partners (typically the ability to compromise and communicate), children of divorced parents may adopt the same behavioral patterns that then undermine the quality and stability of their relationships (Amato 1996; Storksen et al. 2007). If both partners have experienced parental divorce, the intergenerational transmission of divorce might be reinforced, because neither of the partners can balance out (compensate for) the other's poor relationship skills. Thus, parental divorce on both sides of a couple might have multiplicative, not only additive, effects if poor interpersonal skills compound and spiral into conflict (c.f. Erola and Kilpi-Jakonen 2017). 
Genetic and health-related factors are another set of mechanisms through which divorce can be transmitted from one generation to the next. Shared genetic factors between siblings account for some of the intergenerational transmissions of divorce (McGue and Lykken 1992). Additionally, children's psychological and health problems are linked to parental divorce (Bramlett and Blumberg 2007; Cherlin et al. 1998; Huurre et al. 2006; Storksen et al. 2007), and health problems are associated with one's higher divorce risk (e.g., Lyngstad and Jalovaara 2010).

The above mechanisms partly play out and are potentially reinforced or ameliorated by the partnership histories preceding divorce. Studies confirm certain factors that elevate divorce risks that are more likely for children of divorce: marrying at an early age (Kulu 2014; Lehrer 2008; Moore and Waite 1981), never marrying, having divorced previously (Amato 2010), and having children from previous partnerships (Teachman 2008). Conflict and scarce material resources in the divorced parental home might trigger early home leaving and early marriage among children of divorce, whereas the experience of parental divorce can both deter children from marrying and lower the barriers for divorce if they do marry. Previous partnership histories may reinforce specific dynamics such that previously separated and divorced individuals are more likely to separate again. In this study, we focus on two aspects of relationship histories preceding divorce: parental divorce homogamy and the impact of parental divorce in both sides of the couple on their dissolution risk in cohabiting relationships.

Parental divorce homogamy, or family structure homogamy (Wolfinger 2003) might result from emotional closeness and similarity fostered by the shared experience of parental divorce. However, parental divorce homogamy can also appear as a by-product of statustransmission if divorce is more common among parents of lower socio-economic status and children select partners from a similar socio-economic background (Storksen et al. 2007).

There are social, normative, and legal reasons why union dissolution from cohabitation and marriage differ, and why parental divorce might affect them differently. Concerning social aspects, cohabiters are, on average, younger, economically less advantaged, and less likely to be parents, all factors that increase separation risks (Jalovaara 2013). Normative barriers to dissolve cohabitations are lower compared to divorce from marriage and there are no legal requirements. Marriage is generally interpreted as a signal of strong commitment (PerelliHarris et al. 2014). Even in Scandinavian countries, married couples report higher commitment and higher levels of relationship quality compared to cohabiters (Wiik et al. 2009). Married couples benefit from stronger social support and experience stronger social pressure to stay 
together compared to cohabiting couples. Thus union dissolution from cohabitation is much more common. Finally, from a legal point of view, marriage and cohabitation differ in two respects. First, marriage is a legally binding relationship and its dissolution requires formal divorce procedures, while cohabiting relationships end by (simply) moving apart. Married couples are also more likely to have children and own joint property which further strengthens this tie (Jalovaara 2013; Jalovaara and Andersson 2018).

Because marriage is usually preceded by cohabitation, any parental divorce homogamy found in marriages is also likely in cohabitations. Children of divorcees, however, might be more likely to never marry and remain in a cohabiting union or separate from cohabitation. On the one hand, parental divorce might have a greater effect on divorce than on separation from cohabitation and dual parental divorce might contribute relatively little to an already elevated separation risk. In addition, assuming higher separation thresholds in marriages, for both economic and normative reasons, having observed divorce in their parents might make it easier for married couples to pass this elevated threshold compared to cohabiting couples whose baseline separation thresholds are lower. On the other hand, parental divorce from both sides of the couple might increase separation among cohabiters even more compared to married couples, if it reinforces other already elevated risk factors of separation.

Considering the above, we hypothesize that:

H1: Children of divorced parents are more likely to partner with a fellow child of divorce both in cohabiting and married unions (parental divorce homogamy hypothesis).

H2: Children of divorced parents have a higher union dissolution risk in both cohabitation and marriage than those without divorced parents (general parental divorce hypothesis).

H3: Couples where both partners experienced parental divorce have a higher risk of union dissolution in both cohabitation and marriage than those in which only one partner experienced parental divorce (dual parental divorce hypothesis).

H4: Parental divorce on both sides of a couple increases dissolution risk more in marriage than in cohabitation (union type hypothesis).

In particular, we are interested in whether parental divorce on both sides of the couple has a multiplicative effect or an additive effect on their offspring's dissolution risk. A multiplicative effect has been interpreted as a compound effect suggesting poor interpersonal skills (Amato 1996; Wolfinger 2003). Instead, an additive effect would suggest a simple addition of all mechanisms of intergenerational divorce transmission from both sides of the couple and not 
necessarily that poor interpersonal skills spiral into conflict. While we are unable to disentangle all mechanisms driving intergenerational divorce transmission, we can account for parental and offspring education as indicators of status transmission and include extensive information on partnership histories preceding offspring divorce.

\section{Finland}

Finland is an interesting context in which to study intergenerational divorce transmission for several reasons. First, it is a forerunner of the changes in partnership dynamics associated with the second demographic transition (Guzzo 2014; Lesthaege 2010). Other countries are likely to follow at least some of these trends. In Finland, creating a family has been increasingly delayed with an average age of 31.7 at the time of the first marriage for women and 33.9 for men in 2017 (Statistics Finland 2015, 2018). The average age of divorce equally increased in the past years to 40.6 for women and 42.9 for men in 2017 (Statistics Finland 2018). Cohabitation is a widely accepted form of intimate relationship and it is common for younger adults to cohabit for long periods of time before they marry (if they ever marry) (Jalovaara and Fasang 2020). Nonetheless, marriage remains important as a signal of the highest commitment. Even in Finland, cohabitations dissolve at a much higher rate than marriages (Jalovaara and Kulu 2018). Within the first 10 years of cohabitation, nine relationships out of 10 had either ended in separation or transitioned into marriage, separation being much more likely (Jalovaara 2012; Jalovaara 2013; Jalovaara and Kulu 2018).

Second, the Finnish welfare state provides comparatively generous services and income transfers that buffer against socio-economic consequences of union dissolution for adults and children (Hakovirta 2011). Therefore, we offer insights into parental divorce transmission in a country where its effects can be assumed to be weaker compared to most other affluent democracies. Poverty is not as strongly transmitted by parental divorce in Finland as in other countries with liberal restricted welfare states such as the United States. In Finland, rates of union dissolution (from marriage and cohabitation) are high and separation is widely socially accepted. The association between parental divorce and offspring union dissolution is likely stronger in countries where divorce barriers are higher as it is more stigmatized, less widespread, and has more severe socio-economic consequences. Thus, we expect weaker parental divorce homogamy and that parental divorce on both sides of a couple has a lesser effect (is additive rather than multiplicative) in Finland compared to the United States (Amato 1996; Wolfinger 2003). 


\section{Data \& methods}

In this study, we use high-quality Finnish register data, The Finnish Growth Environment Panel (FinGEP), which is based on a $10 \%$ sample of individuals who lived permanently in Finland in 1980. The data structure for one example case is displayed in Figure 1. First, the index-persons ("Parents") are linked to all their biological children (index-persons' children become our focal "Individuals"). Second, index-persons' children ("Individuals") are linked to each of their opposite-sex ${ }^{1}$ co-residential either cohabiting or married partners ("Partner 1", "Partner 2", "Partner 3") and each partner is linked to their parents ("Partner's parents").

To derive all married and cohabiting partnerships, we selected a subsample of indexpersons' daughters (“Individuals") born between 1969 and 1973 who we follow from ages 18 to 41-45 (i.e., between the years 1987 and 2014). In each year the (adult) daughters are matched with their cohabiting or marital partner if they have one. If we used both sons and daughters, we would inflate our sample by including some relationships twice. We, therefore, derive all relationships by reconstructing the daughters' relationship histories. Since 1987, Finnish registers contain information about the place of residence down to the specific apartment, thereby enabling the linkage of opposite-sex individuals to co-residential couples, even when they are unmarried and childless (see Jalovaara and Kulu 2018). The partners can then be linked to their biological parents.

Unions were followed from their start until (if relevant) their dissolution. We considered all co-residential partnerships that women had between 18 and 41/45. Cohabiting couples enter the analysis when they start to cohabit (move in together) and married couples enter the analysis when they marry. In both cases, right censoring occurs after emigration, a partner's death, or age 41/45 (depending on cohort). For cohabitations, entry into marriage was an additional right censor. The final sample includes 28,021 cohabiting or married couples, who contributed 284,802 total couple-years at risk of union dissolution. Married couples contributed 219,935 couple-years at risk and 4,305 divorces, and cohabiting couples contributed 66,499 couple-years at risk and 10,897 separations. In contrast to survey data, register data does not suffer from nonresponse or memory bias but enables a reliable and representative linkage of couples and both

\footnotetext{
${ }^{1}$ Same-sex unions are not studied because the register data do not allow us to distinguish cohabiting couples from roommates, such as students who share a living facility in order to reduce expenses, and this would be a serious problem in these age groups.
} 
partners' parental divorce. We excluded $1.9 \%$ of the cases because there was no information on the parents of both partners. In almost all of these cases, the parents were born abroad.

Fig. 1 Illustration of data structure: all previous co-residential partnerships and parental information is included between ages 18 and 41/45

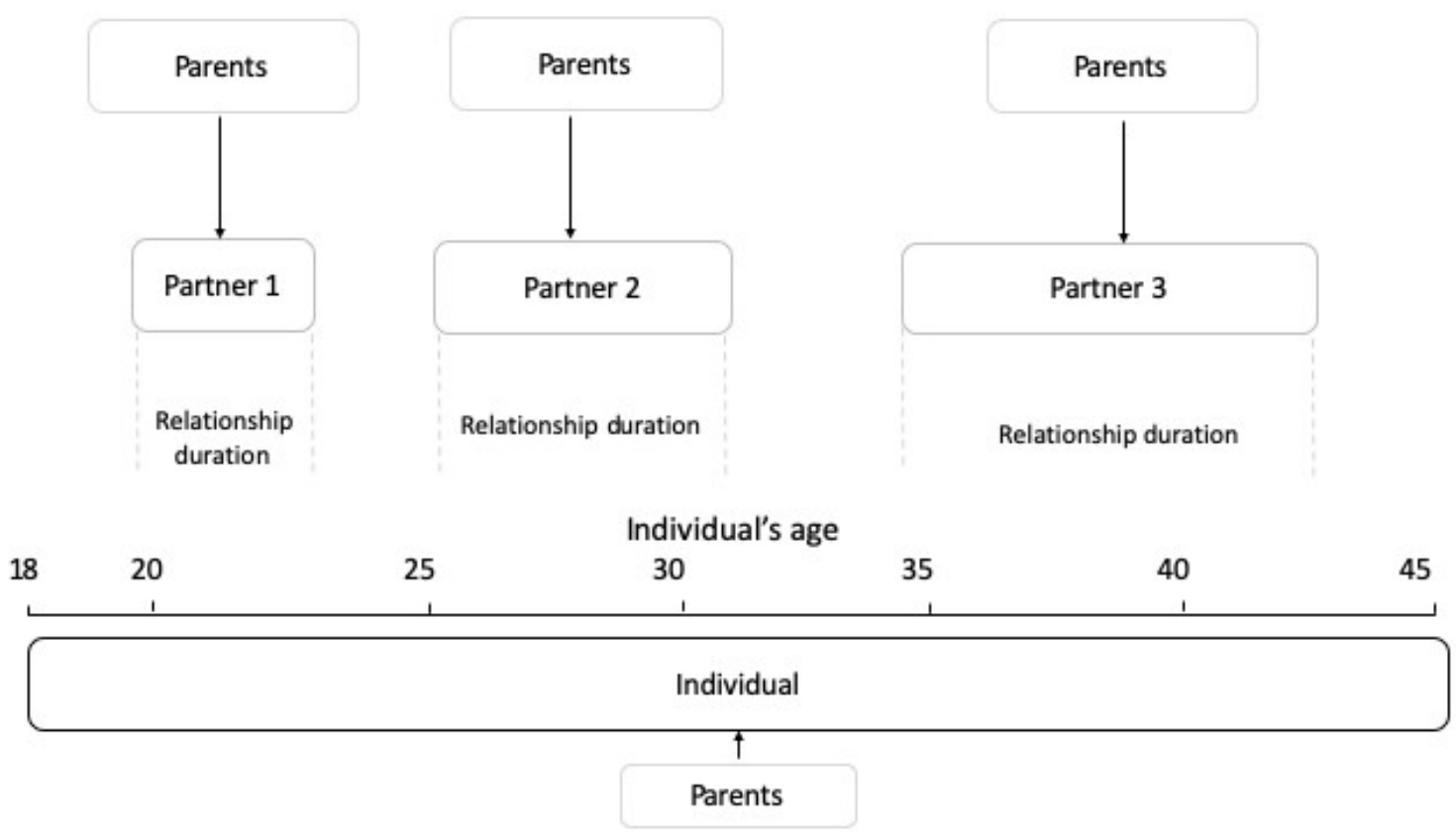

Our main predictor, parental divorce, is operationalized as follows: 0 "not divorced", 1 "female partner's parents divorced", 2 "male partner's parents divorced", and 3 "both partners' parents divorced". The category "not divorced" includes both still married parents and widowed parents. We excluded persons who were born to single mothers, because in such cases, information on the father is often missing, and the present analysis requires information on both parents. After this restriction, less than $1 \%(6,078$ cases) of the parents of the remaining samplepersons were never married or did not have information on both parents and were excluded from the analysis. We included all marriages of biological parents, regardless of whether parents married each other before or after the child was born.

Following the literature, we control for (overview in Table 1): both partners' education (time-varying variable, henceforth ' $t v$ "), both partners' parents' education, age at union formation, union order (tv), partnership duration (time elapsed since entry into either the cohabiting or married partnership, tv), birth cohort, and age of the youngest child in the family 
(tv). Parents' education is time constant and given by the dominance principle (i.e., the highest observed either maternal or paternal education). Parental education is categorized into primary, secondary (including vocational and general tracks), and tertiary education (including those with a bachelor's degree or higher). Both partners' education is coded time-varying as the highest degree attained at each observation point. Their education was categorized into primary, secondary (including vocational and general tracks), lower tertiary education (bachelor's degree), and higher tertiary (master's degree or higher).

In line with previous research, cohabiting couples in our sample dissolve their relationships more often than married couples (Table 1) (e.g., Jalovaara 2013). Partners' and their parents' education levels are lower among cohabiters compared to married partners. Cohabiters have fewer children and more often have experienced parental divorce. Lastly, the mean age of moving in together was slightly lower among married couples.

\section{Methods}

To assess parental divorce homogamy (hypothesis 1), we first calculated logistic regression models on the probability of entering a cohabiting or married relationship with a woman whose parents were divorced. The central independent variable was whether the male partner's parents were also divorced. To assess the association between parental divorce and offspring dissolution risk (hypotheses 2, 3, and 4), we used piecewise constant exponential event history models that divide the time axis into one-year intervals (Blossfeld et al. 2009). The baseline hazard is assumed constant within each one-year interval, but can vary flexibly without assuming any specific functional form between intervals.

For some women, we observe multiple partnerships, as separation is a potentially recurring event. Women who separate multiple times might differ from women who do not based on unobserved factors. Furthermore, previous separations tend to increase the risk of future ones. We followed two strategies to account for potential bias due to unobserved factors and recurring separations. First, we ran the entire analysis taking into account only the first cohabitation and the first marriage (ananlysis available from authors). The results remained substantively the same. Second, we ran all models including a "frailty" term, a woman-level random effect that controls for the time-invariant unmeasured characteristics of a woman (or unobserved heterogeneity) that could influence the hazard of union dissolution for any of her partnerships, for example, personality traits or inter-personal behavior. We tested both gamma and inverse Gaussian-distributed shared frailty, but the results were similar. Table A1 in the appendix 
Table 1 Descriptive information (distribution of couple-years at risk)

\begin{tabular}{|c|c|c|c|}
\hline Variable & & $\begin{array}{c}\text { Cohabitation* } \\
\%\end{array}$ & $\begin{array}{c}\text { Marriage } \\
\%\end{array}$ \\
\hline Union dissolution & & 14 & 2 \\
\hline \multicolumn{4}{|l|}{ Parental divorce } \\
\hline & Not divorced & 54 & 67 \\
\hline & $\begin{array}{l}\text { Female partner's parents } \\
\text { divorced } \\
\text { Male partner's parents }\end{array}$ & 18 & 15 \\
\hline & divorced & 19 & 14 \\
\hline & Both divorced & 8 & 4 \\
\hline \multicolumn{4}{|l|}{ Age of the youngest child } \\
\hline & Childless & 56 & 27 \\
\hline & 0-12 months & 6 & 12 \\
\hline & $1-3$ years & 15 & 26 \\
\hline & 4-10 year & 16 & 27 \\
\hline & $11-$ years & 7 & 8 \\
\hline \multicolumn{4}{|l|}{ Female partner's education } \\
\hline & primary & 15 & 8 \\
\hline & secondary & 49 & 38 \\
\hline & lower tertiary & 29 & 37 \\
\hline & higher tertiary & 7 & 17 \\
\hline \multicolumn{4}{|l|}{ Male partner's education } \\
\hline & primary & 21 & 12 \\
\hline & secondary & 57 & 48 \\
\hline & lower tertiary & 17 & 25 \\
\hline & higher tertiary & 5 & 15 \\
\hline \multicolumn{4}{|c|}{ Education female partner's parents } \\
\hline & primary & 33 & 28 \\
\hline & secondary & 56 & 57 \\
\hline & tertiary & 11 & 15 \\
\hline \multicolumn{4}{|c|}{ Education male partner's parents } \\
\hline & primary & 37 & 33 \\
\hline & secondary & 52 & 85 \\
\hline & tertiary & 11 & 15 \\
\hline & & \multicolumn{2}{|c|}{ Mean (Std) } \\
\hline Union order & & $1.4(0.9)$ & $1.2(0.6)$ \\
\hline Partnership duration & & $5.1(5.4)$ & $8.8(6.2)$ \\
\hline Age at moving in together & & $25.0(5.8)$ & $23.8(4.3)$ \\
\hline
\end{tabular}

*never-married cohabiters 
presents gamma-distributed shared frailty which is widely used in the literature because it has a flexible shape and is analytically tractable (Gutierrez 2002). The results remained substantively the same with and without frailty. We, therefore, conclude that unobserved time-invariant characteristics and recurring separations do not seem to bias our estimates of separation risks to a substantive degree. Below we present models without the frailty term. Stata 15.1 was used for the data analysis.

\section{Results}

\section{Do children of divorce partner more with each other?}

Table 2 shows logistic regression models on the probability to cohabit or marry a woman whose parents are divorced to assess parental divorce homogamy (hypothesis 1). The estimates suggest considerable parental divorce homogamy that is even stronger in marriages compared to cohabitations. Net of controls, men whose parents are divorced are $13 \%$ more likely to cohabit with a woman whose parents are also divorced and $17 \%$ more likely to marry a woman who experienced parental divorce. The effect strength of the male partner's parental divorce is comparable to the negative effect of the female partner having a secondary compared to a primary education, or the female partner's parents having a tertiary relative to a primary education. Note that a male partner's tertiary education reduced their likelihood to partner with a woman whose parents divorced to a much greater extent by almost $60 \%$ compared to male partners that hold only a primary education. Overall effects of offspring and parents' education suggest that status transmission likely plays an important role in parental divorce homogamy but cannot account for all of it. Because children of divorcees often partner with each other, it is even more important to take into account parental divorce on both sides of a couple when studying the intergenerational transmission of divorce.

How does parental divorce from both sides of the couple affect separation risks in cohabitation and marriage?

Figure 2 shows Kaplan Meier survival curves for separation from cohabitation (top) and marriage (bottom) by parental divorce status. In line with the previous literature, cohabitations dissolve at a higher rate and more quickly than marriages (Figure 2). In addition, differences in separation risks affected by parental divorce status are more pronounced for marriages than for 
Table 2 Parental divorce homogamy: Men's likelihood to partner with a woman whose parents are divorced. Logit-model, Odds-ratios (OR), and 95\% confidence intervals $(95 \% \mathrm{CI})$

\begin{tabular}{lcccc}
\hline & \multicolumn{2}{c}{ Cohabitation } & \multicolumn{2}{c}{ Marriage } \\
\hline & OR & $95 \%$ CI & OR & 95\% CI \\
\hline Male partner's parents divorced & 1.13 & $1.08-1.17$ & 1.17 & $1.14-1.20$ \\
Year of birth & 1.05 & $1.04-1.06$ & 1.02 & $1.01-1.02$ \\
Age at union formation & 0.99 & $0.98-0.99$ & 0.99 & $0.99-1.00$ \\
Union order & 1.10 & $1.08-1.13$ & 1.13 & $1.11-1.15$ \\
Child & & & & \\
& 0.94 & $0.91-0.98$ & 0.91 & $0.89-0.93$
\end{tabular}

Female partner's edu (ref: primary)

$\begin{array}{rcccc}\text { secondary } & 0.85 & 0.81-0.90 & 0.81 & 0.77-0.84 \\ \text { lower tertiary } & 0.81 & 0.76-0.85 & 0.75 & 0.72-0.78 \\ \text { higher tertiary } & 0.61 & 0.56-0.67 & 0.62 & 0.59-0.66\end{array}$

Male partner's edu (ref: primary)

$\begin{array}{rrrrr}\text { secondary } & 0.53 & 0.50-0.55 & 0.66 & 0.64-0.68 \\ \text { lower tertiary } & 0.35 & 0.33-0.37 & 0.48 & 0.47-0.50 \\ \text { higher tertiary } & 0.33 & 0.29-0.36 & 0.43 & 0.41-0.44\end{array}$

Female partner's parents' edu (ref: primary)

$\begin{array}{ccccc}\text { secondary } & 1.03 & 0.99-1.07 & 0.99 & 0.97-1.01 \\ \text { tertiary } & 1.24 & 1.17-1.32 & 1.14 & 1.10-1.19\end{array}$

Male partner's parents' edu (ref: primary)

secondary $\quad 1.54 \quad 1.49-1.60 \quad 1.61 \quad 1.57-1.65$

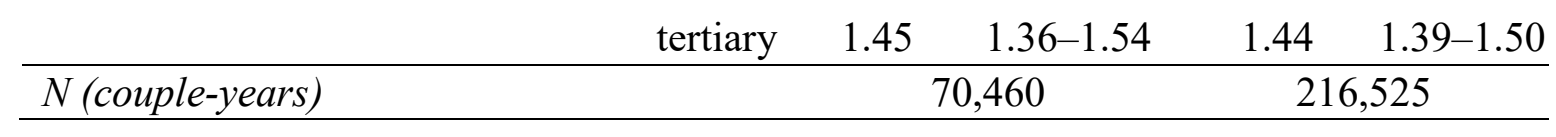


Figure 2 Kaplan-Meier survival curves on union dissolution from cohabitation (top) and marriage (bottom) by parental divorce status.
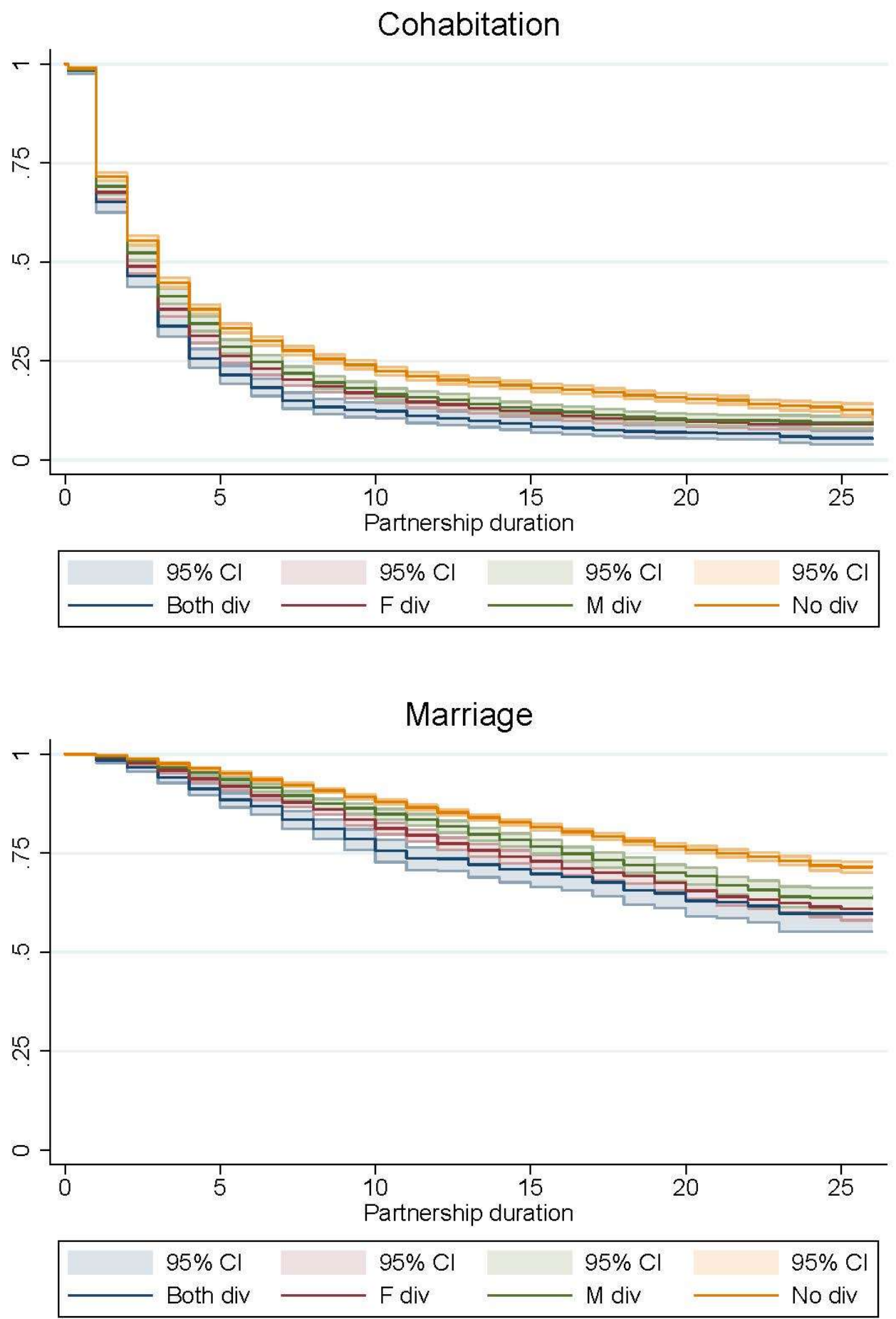

Notes: Partnership duration is cohabitation duration for cohabitations, and marriage duration for marriages. 
cohabitations. Couples where both partners experienced parental divorce show the highest divorce risks, followed by couples where only one partner experienced parental divorce. The final measurement in this figure shows divorce risks for couples where neither of the partner's parents are divorced. The Kaplan-Meier survival estimates are thereby in line with hypotheses 2 (general parental divorce hypothesis), 3 (dual parental divorce hypothesis), and 4 (union type hypothesis).

Table 3 shows exponential piecewise constant models for dissolution risks from cohabitation and marriage. In line with hypotheses 2 and 3, among both cohabiting and married couples, the risk of separation was higher for couples where both partners' parents had divorced, compared to couples where just one partner, or neither of the partners, had experienced parental divorce (Model 0 in Table 3). Parental divorce on both sides of the couple increased the risk of union dissolution more among married than among cohabiting couples (hypothesis 4). For married couples, when one of the partners' parents were divorced compared to neither, we observe a $28-35 \%$ increase in the risk of divorce. If both partners' parents were divorced, the risk of offspring divorce increased by $70 \%$ (see appendix Table A2, effect strength marriage). For cohabiting couples, the difference in the effects of the parental divorce status is much lower: an $8-13 \%$ higher risk for union dissolution if one of the partners' parents is divorced and a 20\% increase if both of the partners' parents are divorced (Appendix Table A2, effect strength cohabitation). When all control variables were included (full model in Table 3), the differences between parental divorce status slightly diminished, especially for married couples, compared to the raw effects. Including the education of parents and offspring led to the largest reduction in effect strength of parental divorce, suggesting that some of the transmission of divorce can be attributed to status transmission, but notable effects remain.

The increase in separation risks due to parental divorce on both sides of the couple is almost exactly twice as high as when only one partners' parents are divorced, clearly supporting an additive and not a multiplicative effect in Finland. We further tested whether there is any indication of a multiplicative effect on separation risk due to dual parental divorce by including an interaction term between the male and female partners' parental divorce. The interaction term proved close to zero for both cohabitations and marriages (see appendix Table A3). Contrary to previous studies supporting a multiplicative effect with a triple increase in the United States (Amato 1996; Wolfinger 2003) and an almost triple increase in Norway (Storksen et al. 2007), for our study cohorts in Finland, we find strong evidence for a merely 
Table 3 Parental divorce and union dissolution: exponential piecewise constant model, hazard ratios (HR) with $95 \%$ confidence intervals $(\mathrm{CI})$

Model 0

Full model

Model 0

Full model

$\mathrm{HR} \quad 95 \% \mathrm{CI} \quad \mathrm{HR} \quad 95 \% \mathrm{CI} \quad \mathrm{HR} \quad 95 \% \mathrm{CI} \quad \mathrm{HR} \quad 95 \% \mathrm{CI}$

Parental divorce (ref: both divorced)

$\begin{array}{rccccccccc}\text { F parents divorced } & 0.88 & (0.82-0.95) & 0.93 & (0.86-0.99) & 0.74 & (0.64-0.85) & 0.81 & (0.79-0.94) \\ \text { M parents divorced } & 0.85 & (0.79-0.92) & 0.89 & (0.82-0.96) & 0.64 & (0.56-0.75) & 0.75 & (0.65-0.87) \\ & & & & & & & & & \\ \text { Not divorced } & 0.74 & (0.69-0.80) & 0.82 & (0.76-0.88) & 0.44 & (0.39-0.50) & 0.59 & (0.52-0.68)\end{array}$

Partnership duration ${ }^{1}$

$\begin{array}{ccccccccc}0 & 0.44 & (0.41-0.47) & 0.90 & (0.85-0.95) & 0.01 & (0.01-0.02) & 0.06 & (0.05-0.09) \\ 1 & 0.37 & (0.34-0.39) & 0.76 & (0.65-0.88) & 0.03 & (0.02-0.04) & 0.13 & (0.09-0.17) \\ 2 & 0.31 & (0.28-0.33) & 0.72 & (0.67-0.77) & 0.04 & (0.03-0.04) & 0.16 & (0.12-0.22) \\ 3 & 0.26 & (0.24-0.28) & 0.70 & (0.65-0.75) & 0.04 & (0.03-0.04) & 0.18 & (0.14-0.24) \\ 4 & 0.21 & (0.19-0.23) & 0.70 & (0.65-0.75) & 0.04 & (0.03-0.04) & 0.19 & (0.14-0.26) \\ 5 & 0.18 & (0.16-0.20) & 0.69 & (0.59-0.80) & 0.04 & (0.03-0.05) & 0.23 & (0.17-0.30) \\ 6 & 0.14 & (0.12-0.16) & 0.55 & (0.46-0.65) & 0.04 & (0.03-0.05) & 0.21 & (0.16-0.28) \\ 7 & 0.13 & (0.11-0.15) & 0.51 & (0.43-0.61) & 0.04 & (0.03-0.05) & 0.20 & (0.15-0.27) \\ 8 & 0.11 & (0.09-0.13) & 0.44 & (0.37-0.54) & 0.04 & (0.03-0.05) & 0.22 & (0.17-0.30) \\ 9 & 0.08 & (0.07-0.09) & 0.32 & (0.26-0.40) & 0.04 & (0.03-0.05) & 0.18 & (0.13-0.24) \\ 10 & 0.09 & (0.08-0.11) & 0.37 & (0.30-0.45) & 0.04 & (0.03-0.04) & 0.17 & (0.17-0.15) \\ 11 & 0.07 & (0.06-0.09) & 0.28 & (0.22-0.36) & 0.04 & (0.03-0.04) & 0.16 & (0.12-0.22) \\ 12 & 0.05 & (0.04-0.07) & 0.20 & (0.14-0.24) & 0.04 & (0.03-0.04) & 0.16 & (0.12-0.22) \\ 13 & 0.05 & (0.04-0.07) & 0.18 & (0.12-0.22) & 0.04 & (0.03-0.04) & 0.16 & (0.12-0.22) \\ 14 & 0.05 & (0.04-0.07) & 0.17 & (0.11-0.22) & 0.03 & (0.02-0.04) & 0.14 & (0.11-0.19)\end{array}$




$\begin{array}{rrrrrrrrrr}15 & 0.05 & (0.04-0.07) & 0.16 & (0.09-0.18) & 0.04 & (0.03-0.04) & 0.13 & (0.10-0.18) \\ 16-19 & 0.34 & (0.24-0.48) & 0.86 & (0.60-1.26) & 0.42 & (0.34-0.52) & 1.63 & (1.19-2.24) \\ 20-26 & 0.22 & (0.13-0.37) & 0.45 & (0.27-0.76) & 0.15 & (0.12-0.20) & 0.52 & (0.37-0.74)\end{array}$

Year of birth

Age at union formation

Union order

Child's age (ref. no child)

$$
\begin{aligned}
& \text { 0-12 months } \\
& \text { 1-3 years } \\
& \text { 4-10 years } \\
& 11-\text { years }
\end{aligned}
$$

F partner's edu ${ }^{2}$

$$
\begin{array}{r}
\text { secondary } \\
\text { lower tertiary } \\
\text { higher tertiary }
\end{array}
$$

M partner's edu ${ }^{2}$

$$
\begin{array}{r}
\text { secondary } \\
\text { lower tertiary } \\
\text { higher tertiary }
\end{array}
$$

F partner's parents' edu ${ }^{2}$

$$
\begin{gathered}
\text { secondary } \\
\text { tertiary }
\end{gathered}
$$

M partner's parents' edu ${ }^{2}$

$$
\begin{array}{cc}
X & \\
0.94 & (0.93-0.95) \\
1.18 \quad(1.15-1.22)
\end{array}
$$

$\mathrm{X}$

0.96

1.37

(0.95-0.97)

(1.30-1.43)

$$
0.31 \quad(0.27-0.35)
$$$$
0.52 \quad(0.49-0.56)
$$$$
0.79 \quad(0.73-0.86)
$$$$
2.03 \quad(1.89-2.19)
$$

0.20

(0.16-0.24)

$0.59 \quad(0.54-0.65)$

$1.04 \quad(0.95-1.15)$

1.28

(1.09-1.50)

$0.92 \quad(0.86-0.97)$

0.68

(0.61-0.75)

$0.92 \quad(0.86-0.98)$

$0.59 \quad(0.53-0.66)$

$0.96 \quad(0.86-1.07)$

$0.58 \quad(0.50-0.68)$

$0.91 \quad(0.86-0.95)$

$0.79 \quad(0.72-0.87)$

$0.88 \quad(0.82-0.94)$

$0.76 \quad(0.68-0.86)$

$0.96 \quad(0.86-1.08)$

$0.79 \quad(0.68-0.92)$

$1.13 \quad(1.07-1.18)$

$1.01 \quad(0.93-1.09)$

$1.29 \quad(1.20-1.39)$

$1.22 \quad(1.09-1.37)$

secondary
tertiary
$1.01 \quad(0.94-1.09)$
$1.04 \quad(0.93-1.17)$

${ }^{1}$ From the beginning of cohabitation or marriage; ${ }^{2}$ Reference: primary educati 
additive increase of separation risks when parents on both sides of a couple are divorced. This is in line with a generally weaker intergenerational divorce transmission in contexts such as Finland, where cohabitation and separation are wide-spread, socially accepted, and the economic consequences of divorce are mitigated by a generous welfare state based on individualized benefits.

Adding to previous studies that only focus on the impact of dual parental divorce on divorce from marriage, we further show that the association between parental divorce and offspring separation risk differs between cohabitation and marriage. Parental divorce increases separation risk more for married couples than for cohabiting couples, thus supporting hypothesis 4 . Although our data do not allow us to clearly disentangle the mechanisms driving the effect heterogeneity of dual parental divorce for cohabitation and marriage, we can be confident that birth cohort, offspring and parental education (status transmission), as well as age at union formation, union order, and the age of the youngest child in the family (preceding relationship history) do not account for these differences.

\section{Conclusion}

This study aims to assess how parental divorce on both sides of a couple affects the couple's partnering dynamics more broadly. Specifically, we considered 1) parental divorce homogamy in partner selection, and the dissolution of both 2) cohabiting and 3) married unions in response to parental divorce on both sides of a couple. To our knowledge, only three previous studies, two in the United States (Amato 1996; Wolfinger 2003) and one in Norway (Storksen et al. 2007), have examined the impact of parental divorce from both sides of a couple. Our study is the first to consider individuals' entire history of co-residential partnerships and to investigate the differences between cohabitations and marriages.

We add to the literature in three ways. First, we show that parental divorce from one or both sides of a couple does not only elevate offspring divorce risk, but also drives parental divorce homogamy and elevates the couple's separation risks in both cohabitation and marriage. Our data allows us to include all co-residential partnerships regardless of marital status which is rarely done as data on cohabitations and parents of cohabiting partners over longer periods is usually unavailable. The mechanisms transmitting union dissolution, therefore, also operate and are reinforced along different stages of the partnership history preceding union dissolution. Because children of divorce are more likely to partner with each other, the elevated separation risks when both partners' parents are divorced is relevant for a larger share of the population. It 
is therefore important to study intergenerational divorce transmission on the couple level, instead of focusing on the parent-child dyad of one partner only.

Second, together with previous studies, our findings provide insight into the contextual driving forces of the impact of both partners' parental divorce on offspring family formation at a country-wide level. In Finland, a forerunner of the second demographic transition, cohabitation and separation are common, widely socially accepted, and not economically dangerous. In line with previous research (Dronkers and Härkönen 2008; Kalmijn and Uunk 2007), we also find weaker effects of dual parental divorce along several stages of the family formation process. Wolfinger (2003) found that parental divorce increased the likelihood of choosing a partner whose parents are also divorced by $58 \%$ without controls and $31 \%$ including a broad set of controls in the United States. In contrast, we merely found a $13 \%$, and a $17 \%$ increase in choosing a partner whose parents are also divorced for cohabitation and marriage, respectively, including a relatively narrow set of controls. The effect strength of parental divorce homogamy in marriage in Finland roughly corresponds to half of the effect strength found for the United States. Moreover, contrary to previous studies for the United States and Norway (Amato 1996; Storksen et al. 2007; Wolfinger 2003), we found a merely additive (double) and not multiplicative (triple) effect of parental divorce from both sides of a couple on their separation risk from both cohabitations and marriages. Previous studies have interpreted the multiplicative effect as poor interpersonal skills that cumulatively spiral into conflict and separation. While we could not directly measure interpersonal skills, our findings for Finland do not support such an interpretation. Rather, it seems that all mechanisms that transmit separation from one generation to the next simply add up for both cohabitations and marriages in Finland. Associations between both partners' parental divorce and offspring union dissolution are likely stronger in countries where cohabitation and separation are more stigmatized, less wide-spread and the welfare state does not buffer its socio-economic consequences.

Third, to our knowledge, we present the first study that compares the effect of parental divorce from both sides of a couple on dissolution risks in both cohabiting and married relationships. Examining cohabitation is gaining importance as it proliferates as a substitute, not only a prelude, for marriage and is associated both with lower socio-economic standing and higher baseline union dissolution risks (Jalovaara 2013). In addition, children of divorcees are more likely to never marry (Storksen et al. 2007), but cohabit instead. If dual parental divorce is concentrated among cohabiting couples, elevating their separation risk, this could additionally reinforce cohabiting couples' socio-economic disadvantages compared to married couples. This 
is not supported by our findings. Instead, we show that both the effects of parental divorce homogamy and divorce transmission from one or both sides of the couple are stronger in marriages than in cohabitations. It seems that the same event, divorce from marriage, is more strongly transmitted across generations. The stronger normative signal of commitment attached to marriage likely creates a higher threshold for divorce, in addition to the legal and economic burdens associated with divorce compared to dissolving a cohabiting union. Further, having observed one's parents' divorce might encourage offspring to go through with divorce instead of remaining in a possibly unsatisfactory partnership. Separation risks from cohabitation are generally higher and other factors appear to be more influential compared to parental divorce, albeit it also notably increases separation risks for cohabiting unions. Indeed, we would miss crucial information about the separation of co-residential unions due to dual parental divorce if we only focused on offspring divorce from marriage, as has been done in previous studies (Amato 1996; Storksen et al. 2007; Wolfinger 2003).

Our findings have to be interpreted in light of several limitations. First, while the register data allows us to include representative information on parental divorce from both sides of the couple and reconstruct entire partnership histories including all cohabiting unions on a yearly basis over a long period, it contains limited information to disentangle potential mechanisms that drive the intergenerational transmission of divorce. In contrast to survey data, register data do not include information on pro-divorce attitudes and values, interpersonal behaviour, or relationship quality. Children of divorcees may have worse relationship skills, differ in personality traits that are inherited from divorce-prone parents, have lower levels of commitment, and lower thresholds for separation if a partnership proves unhappy (Amato 2010). If both partners experienced parental divorce, conflicts might accumulate (Wolfinger 2003) due to all or only some of these factors. Recent evidence (Gager et al. 2016) suggests that it is not the parental divorce per se (i.e., change in family structure) that increases offspring dissolution risk, but rather parental conflict and the poor relationship quality that preceded the divorce. Gager and colleagues (2016) show that parental conflicts increase offspring separation risks irrespective of parental divorce. Interestingly, children who grew up in high conflict families and experienced parental divorce did not have an elevated separation risk compared to children from low conflict families who stayed together. However, children, who grew up in high conflict families from which parents did not divorce, had higher separation risks. Lacking information on relationship quality, interpersonal behavior, and attitudes, the register data do not allow for testing these 
mechanisms in relation to dual parental divorce. This should be further investigated using survey and qualitative data.

Second, we could not statistically compare our data of the lower effect strength of parental divorce from both sides of a couple in Finland to previous studies or other countries. Still, assuming that the US and Norwegian data are also reasonably representative, the much lower effect strength of parental divorce in Finland found in our study strongly suggests that intergenerational divorce transmission is weaker at various stages of family formation compared to the United States and Norway. Lower effect strength for Finland compared to the United States is in line with the cross-nationally comparative divorce literature suggesting that intergenerational continuity in union dissolution is lower in contexts where separation is more wide-spread, less socially stigmatized, and its socio-economic consequences are less severe (Dronkers and Härkönen 2008; Kalmijn and Uunk 2007). Against this backdrop, the relatively stronger effects found by Storksen et al. (2007) for Norway are somewhat puzzling. Harmonized cross-national longitudinal data accounting for changes in the family constellations of partners would allow for directly testing differences in effect strength and estimating country interaction effects.

Third, our information on parental relationship histories was limited. We were unable to include parental separation from cohabitation, as cohabitations can only reliably be identified in the Finnish registers from 1987 onwards. It is possible that offspring separation risks from cohabitation are more affected by parental separation than divorce, if indeed transmission of the same demographic event is particularly strong. Note, however, that cohabitations were less widespread among the parent generation and therefore possibly played only a minor role compared to generations to come. Moreover, our data does not allow us to precisely locate the children's age when their parents got divorced. Previous studies suggest that parental divorce early in the child's life is particularly consequential for later life outcomes (Amato 1996). Finally, due to the set up of our research design, we only observe relatively early separations and divorces before ages 41-45. For Norway, Storksen et al. (2007) shows that the impact of parental divorce on offspring divorce was highest within the first ten years of offspring marriages. These are arguably well covered in our data, given an average first marriage age of about 32 and average age of divorce of 41 . Yet, the associations found in our study might differ for later life and higherorder union dissolutions. Future research is needed to assess how the timing of single or dual parental divorce in the child's life matters for their family formation and how these associations vary across countries. 
We conclude that not taking into account how parental divorce from both sides of a couple affects their broader family formation processes risks underestimating the consequences of parental divorce for demographic behavior and associated socio-economic outcomes. The coincidence of parental divorce from both sides of a couple is systematically elevated with notable parental divorce homogamy and it additively increases separation risks to a greater extent in marriages than in cohabitations even in a generous welfare state with liberal family values such as Finland. Analyzing multigenerational dynamics of wider kinship and in-law networks as determinants of demographic behavior and socio-economic outcomes (Kailaheimo-Lönnqvist et al. 2019; Mare 2011) as well as systematically assessing their cross-national variation remain important tasks for future research.

\section{Acknowledgements}

The research was funded by the Academy of Finland (decisions 321264 and 320162), ECSRsociety (research exchange grant), University of Turku, Freie Universität Berlin, WZB Berlin Social Science Center and Humboldt University of Berlin. We thank Statistics Finland for the permission (TK-53-507-12) to use their data. Warm thanks to those who have provided comments in the Writing workshop in WZB 2020.

\section{References}

Amato, P. R. (1996) Explaining the Intergenerational Transmission of Divorce Published by: National Council on Family Relations Explaining the Intergenerational Transmission of Divorce. Journal of Marriage and Family 58(3): 628-640.

Amato, P. R. (2010) Research on divorce: Continuing trends and new developments. Journal of Marriage and Family, doi:10.1111/j.1741-3737.2010.00723

Amato, P. R, \& DeBoer D. D. (2004) The transmission of Marital Instability across generations. Journal of Marriage and Family, doi:10.1111/j.1741-3737.2001.01038

Avellar, S., \& Smock, P. J. (2005) Of the Dissolution of Cohabiting Unions. Journal of Marriage and Family, doi:10.1111/j.0022-2445.2005.00118

Blossfeld, H. P., Golsch, K., \& Rohwer, G. (2009) Event History Analysis with Stata. London: Psychology Press.

Bramlett, M. D., \& Blumberg, S. J. (2007) Family structure and children's physical and mental 
health. Health Affairs, doi:10.1377/hlthaff.26.2.549

Breusch, T., \& Gray, E. (2004) Does marriage improve the wages of men and women in Australia? Australian Population Association (September 2004): 15-17. Available at: https://www.melbourneinstitute.com/downloads/hilda/Bibliography/Conference_Papers/B reusch_APA_2004-7D.pdf.

Cherlin, A. J., Chase-Lansdale, L., \& McRae, C. (1998) Effects of parental divorce on mental health throughout the life course. Journal of Divorce and Remarriage, doi: $10.2307 / 2657325$

Cherlin, A. J. (2010) Demographic trends in the United States: A review of research in the 2000s. Journal of Marriage and Family, doi:10.1111/j.1741-3737.2010.00710

de Graaf, P. M., \& Kalmijn, M. (2006) Change and stability in the social determinants of divorce: A comparison of marriage cohorts in the Netherlands. European Sociological Review, doi:10.1093/esr/jc1010

Diekmann, A., \& Schmidheiny, K. (2013) The intergenerational transmission of divorce: A fifteen-country study with the fertility and family survey. Comparative Sociology, doi:10.1163/15691330-12341261

Dronkers, J., \& Härkönen, J. (2008) The intergenerational transmission of divorce in crossnational perspective: Results from the Fertility and Family Surveys. Population Studies, doi:10.1080/00324720802320475

Erola, J., \& Kilpi-Jakonen, E. (2017) Compensation and other forms of accumulation in intergenerational social inequality. In J. Erola \& E. Kilpi-jakonen (Ed.) Social Inequality Across the Generations (pp. 3-24) Cheltenham, UK: Edward Elgar.

Fasang, A. E., \& Raab, M. (2014) Beyond transmission: Intergenerational patterns of family formation among middle-class American families. Demography, doi:10.1007/s13524-0140322-9

Gager, C. T., Yabiku, S. T., \& Linver, M. R. (2016) Conflict or divorce? Does parental conflict and/or divorce increase the likelihood of adult children's cohabiting and marital dissolution? Marriage and Family Review, doi:10.1080/01494929.2015.1095267

Glenn, N. D., \& Kramer, K. B. (1987) The marriages and divorces of the children of divorce. Journal of Marriage and the Family, doi:10.2307/351974 
Gutierrez, R. G. (2002) Parametric Frailty and Shared Frailty Survival models. The Stata Journal: Promoting Communications on Statistics and Stata, doi: $10.1177 / 1536867 \times 0200200102$

Guzzo, K. B. (2014) Trends in cohabitation outcomes: Compositional changes and engagement among never-married young adults. Journal of Marriage and Family, doi:10.1111/jomf.12123

Hakovirta, M. (2011) Child maintenance and child poverty: A comparative analysis. Journal of Poverty and Social Justice, doi:10.1332/175982711X596991

Hübgen, S. (2018) ‘Only a husband away from poverty?' Lone mothers' poverty risk in a European comparison. In: L. Bernardi \& D. Mortelmans (Ed.) Lone Parenthood in the Life Course (pp. 167-190). Cham: Springer.

Huurre, T., Junkkari, H., \& Aro, H. (2006) Long-term psychosocial effects of parental divorce: A follow-up study from adolescence to adulthood. European Archives of Psychiatry and Clinical Neuroscience, doi:10.1007/s00406-006-0641-y

Jalovaara, M. (2001) Socio-economic status and divorce in first marriages in Finland 1991-93. Population Studies, doi:10.1080/00324720127685

Jalovaara, M. (2012) Socio-economic resources and first-union formation in Finland, cohorts born 1969-81. Population Studies, doi:10.1080/00324728.2011.641720

Jalovaara, M. (2013) Socioeconomic resources and the dissolution of cohabitations and marriages. European Journal of Population / Revue européenne de Démographie, doi:10.1007/s10680-012-9280-3

Jalovaara, M., \& Andersson, G. (2018) Disparities in children's family experiences by mother's socioeconomic status: The case of Finland. Population Research and Policy Review, doi:10.1007/s11113-018-9485-1

Jalovaara, M., \& Fasang, A. E. (2020) Family life courses, gender, and mid-life earnings. European Sociological Review, doi:10.1093/esr/jcz057

Jalovaara, M., \& Kulu, H. (2018) Separation risk over union duration: An immediate itch? European Sociological Review, doi:10.1093/esr/jcy017

Kailaheimo-Lönnqvist, S., Kilpi-Jakonen, E., Tanskanen, A.O., et al. (2019) Behind every successful (wo)man is a successful parent-in-law? The association between resources of 
the partner's parents and individual's occupational attainment. Research in Social Stratification and Mobility, doi:10.1016/j.rssm.2019.100438

Kalmijn, M., \& Uunk, W. (2007) Regional value differences in Europe and the social consequences of divorce: A test of the stigmatization hypothesis. Social Science Research, doi:10.1016/j.ssresearch.2006.06.001

Kulu, H. (2014) Marriage duration and divorce: The seven-year itch or a lifelong itch? Demography, doi:10.1007/s13524-013-0278-1

Lehrer, E. L. (2008) Age at marriage and marital instability: Revisiting the Becker-LandesMichael hypothesis. Journal of Population Economics, doi:10.1007/s00148-006-0092-9

Lesthaege, R. (2010) The unfolding story of the second demographic transition. Population and development review, doi:10.1111/j.1728-4457.2010.00328

Lyngstad, T. H., \& Jalovaara, M. (2010) A review of the antecedents of union dissolution. Demographic Research, doi:10.4054/DemRes.2010.23.10

Mare, R. D. (2011) A multigenerational view of inequality. Demography, doi:10.1007/s13524011-0014-7

McGue, M., \& Lykken, D. T. (1992) Genetic influence on risk of divorce. Psychological Science, doi:10.1111/j.1467-9280.1992.tb00049

Moore, K. A., \& Waite, L. J. (1981) Marital dissolution, early motherhood and early marriage. Social Forces, doi:10.1093/sf/60.1.20

Perelli-Harris, B., Mynarska, M., Berrington, A., et al. (2014) Towards a new understanding of cohabitation: Insights from focus group research across Europe and Australia. Demographic Research, doi:10.4054/DemRes.2014.31.34

Smock, P. J., Manning, W. D., \& Gupta, S. (1999) The effect of marriage and divorce on women's economic well-being. American Sociological Review, doi:10.2307/2657403

Statistics Finland (2015) Ensiavioitujan ja ensisynnyttäjän keski-ikä 1982-2014. Available at: https://www.stat.fi/til/ssaaty/2014/ssaaty_2014_2015-04-21_kuv_001_fi.html.

Statistics Finland (2018) Samaa sukupuolta olevat solmivat 554 avioliittoa. Available at: https://www.stat.fi/til/ssaaty/2017/ssaaty_2017_2018-05-08_tie_001_fi.html.

Steele, F., Kallis, C., Goldstein, H., et al. (2005) The relationship between childbearing and transitions from marriage and cohabitation in Britain. Demography, doi:10.1353/dem. 
2005.0038

Storksen, I., Røysamb, E., Gjessing, H. K., et al. (2007) Marriages and psychological distress among adult offspring of divorce: A Norwegian study. Scandinavian Journal of Psychology, doi:10.1111/j.1467-9450.2007.00601

Teachman, J. (2008) Complex life course patterns and the risk of divorce in second marriages. Journal of Marriage and Family, doi:10.1111/j.1741-3737.2008.00482

Thomson, E. (2014) Family complexity in Europe. Annals of the American Academy of Political and Social Science, doi:10.1177/0002716214531384

Wagner, M., \& Weiß, B. (2006) On the variation of divorce risks in Europe: Findings from a meta-analysis of European longitudinal studies. European Sociological Review, doi:10.1093/esr/jc1014

Wiik, K. A., Bernhardt, E., \& Noack, T. (2009) A study of commitment and relationship quality in Sweden and Norway. Journal of Marriage and Family, doi:10.1111/j.17413737.2009 .00613

Wolfinger, N. H. (2003) Family structure homogamy: The effects of parental divorce on partner selection and marital stability. Social Science Research, doi:10.1016/S0049089X(02)00014-5

Wolfinger, N. H. (2007) Trends in the intergenerational transmission of divorce. Demography, doi: $10.2307 / 2648064$ 


\section{Appendix}

Table A1 Parental divorce and union dissolution. Exponential piecewise constant model, results are reported as hazard ratios (HR) and their $95 \%$ confidence intervals (CI) with woman-level frailty

Cohabitation

Model 0
Marriage

Model 0

Full model

\begin{tabular}{rccccccccc} 
& HR & $95 \% \mathrm{CI}$ & HR & $95 \% \mathrm{CI}$ & HR & $95 \% \mathrm{CI}$ & HR & $95 \% \mathrm{CI}$ \\
\hline Parental divorce (ref: both divorced) & & & & & & & & & \\
F parents divorced & 0.88 & $(0.83-0.96)$ & 0.92 & $(0.86-0.98)$ & 0.75 & $(0.65-0.86)$ & 0.83 & $(0.80-0.96)$ \\
M parents divorced & 0.85 & $(0.79-0.92)$ & 0.90 & $(0.83-0.97)$ & 0.65 & $(0.57-0.76)$ & 0.76 & $(0.66-0.88)$ \\
Not divorced & 0.74 & $(0.67-0.78)$ & 0.82 & $(0.76-0.88)$ & 0.46 & $(0.41-0.52)$ & 0.60 & $(0.53-0.69)$
\end{tabular}

Partnership duration ${ }^{1}$

$\begin{array}{cccccccccc}0 & 0.44 & (0.42-0.48) & 0.91 & (0.86-0.96) & 0.01 & (0.01-0.02) & 0.06 & (0.05-0.09) \\ 1 & 0.37 & (0.36-0.41) & 0.76 & (0.65-0.88) & 0.03 & (0.02-0.04) & 0.13 & (0.09-0.17) \\ 2 & 0.31 & (0.28-0.33) & 0.72 & (0.67-0.77) & 0.03 & (0.03-0.04) & 0.15 & (0.11-0.21) \\ 3 & 0.26 & (0.25-0.29) & 0.71 & (0.66-0.76) & 0.04 & (0.03-0.04) & 0.18 & (0.14-0.24) \\ 4 & 0.21 & (0.20-0.24) & 0.70 & (0.65-0.75) & 0.03 & (0.03-0.04) & 0.19 & (0.14-0.26) \\ 5 & 0.18 & (0.16-0.20) & 0.69 & (0.59-0.80) & 0.03 & (0.03-0.05) & 0.23 & (0.17-0.30) \\ 6 & 0.14 & (0.13-0.17) & 0.56 & (0.47-0.66) & 0.04 & (0.03-0.05) & 0.20 & (0.15-0.27) \\ 7 & 0.13 & (0.11-0.15) & 0.52 & (0.44-0.62) & 0.04 & (0.03-0.05) & 0.20 & (0.15-0.27) \\ 8 & 0.11 & (0.09-0.13) & 0.44 & (0.37-0.54) & 0.04 & (0.03-0.05) & 0.22 & (0.17-0.30) \\ 9 & 0.08 & (0.08-0.10) & 0.32 & (0.26-0.40) & 0.04 & (0.03-0.05) & 0.18 & (0.13-0.24) \\ 10 & 0.09 & (0.08-0.11) & 0.38 & (0.31-0.46) & 0.04 & (0.03-0.04) & 0.17 & (0.17-0.15) \\ 11 & 0.07 & (0.07-0.10) & 0.27 & (0.21-0.35) & 0.04 & (0.03-0.04) & 0.16 & (0.12-0.22) \\ 12 & 0.05 & (0.05-0.08) & 0.20 & (0.14-0.24) & 0.03 & (0.02-0.03) & 0.16 & (0.12-0.22) \\ 13 & 0.05 & (0.04-0.07) & 0.18 & (0.12-0.22) & 0.03 & (0.03-0.04) & 0.15 & (0.11-0.21) \\ 14 & 0.05 & (0.04-0.07) & 0.17 & (0.11-0.22) & 0.02 & (0.01-0.03) & 0.14 & (0.11-0.19)\end{array}$




$\begin{array}{rrrrrrrrrr}15 & 0.05 & (0.04-0.07) & 0.16 & (0.09-0.18) & 0.04 & (0.03-0.04) & 0.13 & (0.10-0.18) \\ 16-19 & 0.34 & (0.25-0.49) & 0.86 & (0.60-1.26) & 0.42 & (0.34-0.52) & 1.63 & (1.19-2.24) \\ 20-26 & 0.22 & (0.13-0.37) & 0.44 & (0.26-0.75) & 0.15 & (0.12-0.20) & 0.52 & (0.37-0.74)\end{array}$

Year of birth

Age at union formation ${ }^{1}$

Union order

Child's age (ref. no child)

$$
\begin{aligned}
& \text { 0-12 months } \\
& \text { 1-3 years } \\
& \text { 4-10 years } \\
& \text { 11- years }
\end{aligned}
$$

F partner's edu ${ }^{2}$

$$
\begin{array}{r}
\text { secondary } \\
\text { lower tertiary } \\
\text { higher tertiary }
\end{array}
$$

M partner's edu ${ }^{2}$

$$
\begin{array}{r}
\text { secondary } \\
\text { lower tertiary } \\
\text { higher tertiary }
\end{array}
$$

F partner's parents' edu ${ }^{2}$

$$
\begin{array}{r}
\text { secondary } \\
\text { tertiary }
\end{array}
$$

M partner's parents' edu ${ }^{2}$

$$
\begin{array}{r}
\text { secondary } \\
\text { tertiary }
\end{array}
$$

X

$0.94 \quad(0.93-0.95)$

$1.18 \quad(1.15-1.22)$

$0.30 \quad(0.26-0.34)$

$0.52 \quad(0.49-0.56)$

$0.80 \quad(0.74-0.87)$

$2.03 \quad(1.89-2.19)$

$0.91 \quad(0.87-0.98)$

$0.92 \quad(0.86-0.98)$

$0.96 \quad(0.86-1.07)$

$0.91 \quad(0.86-0.95)$

$0.89 \quad(0.83-0.95)$

$0.96 \quad(0.86-1.08)$

$1.14 \quad(1.08-1.19)$

$1.29 \quad(1.20-1.39)$
$1.03 \quad(0.98-1.08)$
$1.01 \quad(0.94-1.09)$
$1.23 \quad(1.15-1.32)$
$1.04 \quad(0.93-1.17)$

$1.01 \quad(0.93-1.09)$

$1.22(1.09-1.37)$

$0.20 \quad(0.16-0.24)$

$0.60 \quad(0.56-0.66)$

$1.04 \quad(0.95-1.15)$

$1.28 \quad(1.09-1.50)$

$0.68 \quad(0.61-0.75)$

$0.60 \quad(0.54-0.67)$

$0.59 \quad(0.51-0.69)$

$0.78 \quad(0.71-0.86)$

$0.76 \quad(0.68-0.86)$

$0.79 \quad(0.68-0.92)$

${ }^{1}$ From the beginning of cohabitation or marriage; ${ }^{2}$ Reference: primary education 
Table A2 Parental divorce and union dissolution. Exponential piecewise model, results are reported as hazard ratios (HR) and their $95 \%$ confidence intervals $(95 \% \mathrm{CI})$

\begin{tabular}{lcccc}
\hline & \multicolumn{2}{c}{ Cohabitation } & \multicolumn{2}{c}{ Marriage } \\
\hline Parental divorce (ref: not divorced) & HR & $95 \%$ CI & HR & $95 \%$ CI \\
F divorced & 1.13 & $1.06-1.19$ & 1.35 & $1.24-1.48$ \\
M divorced & 1.08 & $1.02-1.14$ & 1.28 & $1.17-1.41$ \\
Both divorce & 1.20 & $1.12-1.29$ & 1.70 & $1.49-1.94$
\end{tabular}

Controls: Partnership duration, Year of birth, Age at union formation, Union order, Child's age, $\mathrm{F}$ and $\mathrm{M}$ partner's education, $\mathrm{F}$ and $\mathrm{M}$ partner's parents' education

Table A3 Parental divorce and union dissolution. Exponential piecewise model, results are reported as hazard ratios (HR) and their $95 \%$ confidence intervals (95\% CI)

\begin{tabular}{lcccc}
\hline & \multicolumn{2}{c}{ Cohabitation } & \multicolumn{2}{c}{ Marriage } \\
\hline & HR & $95 \%$ CI & HR & $95 \%$ CI \\
F parental div \# M parental div & 0.987 & $0.90-1.11$ & 0.983 & $0.83-1.17$
\end{tabular}

Controls: Partnership duration, Year of birth, Age at union formation, Child's age, Union order, $\mathrm{F}$ and $\mathrm{M}$ partner's education, $\mathrm{F}$ and $\mathrm{M}$ partner's parents' education 